\title{
Original $\mid$ RADIOTHERAPY AND TEMOZOLOMIDE COMPARED WITH Article RADIOTHERAPY ALONE IN NEWLY DIAGNOSED GLIOBLASTOMA MULTIFORME
}

\author{
Ehsan Al-Ghoneimi ${ }^{1}$, Ehab Mostafa ${ }^{2}$, Zeinab Abd El-Hafeez ${ }^{2}$, Hoda Al-Booz ${ }^{2}$, Mohamed \\ Abdullah ${ }^{1}$, Nashwa Nazmy ${ }^{2}$ \\ ${ }^{1}$ Clinical Oncology Department, Faculty of Medicine, Cairo University, ${ }^{2}$ Radiation Oncology and \\ Nuclear Medicine Department, Faculty of Medicine, Ain Shams University
}

\begin{abstract}
Aim of the Work: The current standard of care for patients with glioblastoma multiforme (GBM) is resection followed by radiotherapy. The median survival time for these patients remains at less than 1 year from initial diagnosis. Temozolomide (TMZ) has shown promising activity in the treatment of malignant gliomas. We conducted a multicenter randomized phase III study comparing the efficacy and safety of TMZ administered concomitantly and sequentially to radiotherapy versus radiotherapy alone in patients with newly diagnosed GBM.

Patients and Methods: The present work is a randomized study involving 44 patients with pathologically proved GBM. Eligible patients were randomly assigned to one of two treatment groups, either the standard postoperative radiation, 60 Gy/ 2 Gy /fraction / 6 weeks, (group A) or postoperative concomitant 2 cycles of TMZ, $150 \mathrm{mg} / \mathrm{m}^{2}$ daily for 5 days every 28 days, and radiation followed by 6 cycles of TMZ, $200 \mathrm{mg} / \mathrm{m}^{2}$ daily for 5 days every 28 days, (group B). The primary study end points were overall survival and progression-free survival (PFS). A secondary end point was to document the treatment-related toxicity.

Results: The median survival and PFS were 8.5 months and 6.3 months in radiation group vs. 12.6 months and 10.5 months in chemoradiation group. The overall survival and PFS at 12 months were $23.5 \%$ and $0 \%$ in radiation group vs. $43.5 \%$ and $21 \%$ in chemoradiation group. The differences were statistically significant. TMZ was safe and tolerable. Grade three and four toxicity was not recorded in the radiation group. Toxicity was mainly hematologic in the chemoradiation group.

Conclusion: The results of our study suggested that concomitant radiation and TMZ followed by six cycles of adjuvant TMZ is superior to radiation alone in patients with newly diagnosed GBM. In addition, TMZ was safe and tolerable. Nevertheless, the challenge remains to improve clinical outcomes further.
\end{abstract}

Key words: Glioblastoma multiforme, temozolomide, radiation

\section{INTRODUCTION}

Glioblastoma multiforme $(\mathrm{GBM})$ is the most common and aggressive neoplasia of the brain in adults. These tumors account for $45 \%$ to $50 \%$ of all gliomas. Their clinical course is usually rapid and fatal, with a median survival of less than one year ${ }^{1,2}$. The current standard of care for patients with GBM is resection followed by radiotherapy. Radiotherapy is necessary because of extensive tumor infiltration into normal brain structures makes resection of the entire primary tumor is impossible ${ }^{3,4}$. Two large randomized multicenter trials confirmed that radiotherapy provided significant survival advantage ${ }^{5,6}$. The median survival after surgical resection is about 20 weeks which can be extended to about 36 weeks if additional radiotherapy is received ${ }^{7}$. Despite this documented response essentially $100 \%$ of GBM recur within two- years ${ }^{8}$.
The use of adjuvant chemotherapy after surgery or radiotherapy is still controversial but has been shown to increase median survival and time to progression in some trials 9 . Nitrosoureas for many decades were considered the most effective. Malignant glial cells are resistant to many standard chemotherapeutic agents. One of the mechanisms of resistance to the nitrosoureas is the increased expression of the DNA repair enzymes, O6-methylguanine-DNA methyltransferase $(\mathrm{MGMT})^{10}$. Temozolomide (TMZ) is a novel alkylating agent that has proved to be effective in-patients with recurrent $\mathrm{GBM}^{11-13}$. TMZ has been shown to overcome tumor cell resistance to nitrosoureas by depleting MGMT in multicenter phase II trials ${ }^{14-17}$. In phase I and II clinical trials, TMZ was well tolerated with a favorable toxicity profile, and easily managed noncumultative myelotoxicity ${ }^{13}$. 
Interestingly, in vitro experiments with human GBM cell lines have demonstrated that the combination of $\mathrm{TMZ}$ and radiotherapy have either synergistic or additive inhibitory effect on tumor cell growth ${ }^{18}$. Various schemes and schedules of administration have been investigated, including the neoadjuvant administration of TMZ prior to radiation ${ }^{19-21}$, and the concomitant administration of TMZ with radiation. Recent reports of phase II studies investigating adjuvant TMZ suggested a potential survival benefit ${ }^{2,22-24}$

In our previous pilot study on 18 patients with high grade glioma treated with concomitant postoperative radiotherapy and $\mathrm{TMZ}$, the regimen was safe and tolerable with modest improvement in the median survival and time to progression ${ }^{24}$. However, the results were not promising in GBM compared with these in case of anaplastic astrocytoma (AA). Objective response was achieved in only $45.5 \%$ of patients with GBM, the median survival was 10 months and the median time for progression was 6.4 months. This encouraged us to conduct this prospective randomized study to determine if the concomitant use of TMZ and conventionally fractionated irradiation followed by six cycles of adjuvant chemotherapy can improve more the survival with acceptable level of toxicity compared to the standard surgery and postoperative irradiation alone in GBM patients.

\section{PATIENTS AND METHODS}

The present work is a randomized study involving patients with pathologically proved GBM (WHO classification 1993) presented to Radiation Oncology Departments-Ain Shams University and Cairo University Hospitals, and Sohag Cancer Center between November 2002 and May 2005. Initial evaluation included: History, and physical examination, comprehensive neurological examination, complete blood count, serum chemistries and chest Xray. Local and regional tumor extents were assessed by gadolinium-enhanced magnetic resonance imaging (MRI) and computed tomographic scan (CT). Patients eligible for this study had histologically confirmed GBM either through open biopsy or stereotactic biopsy. Other eligibility criteria included age of at least 18 years but not more than 70 years, performance status $\geq 70$ on Karnofsky scale, normal conscious level, adequate hematologic status, liver function, and kidney function, no prior malignancy, no prior radiotherapy or chemotherapy to the brain, no medical condition which could interfere with oral administration of $\mathrm{TMZ}$ and no concurrent serious medical illness. Each patient gave written informed consent before entering the study.

\section{Treatment Policy:}

Eligible patients were randomly assigned to one of two treatment groups either the standard postoperative radiation (group A) or postoperative concomitant TMZ and irradiation followed by 6 cycles TMZ (group B). All the patients were planned to receive radiotherapy after complete healing of the wound and within 2 weeks if surgery was performed. The patients were treated on megavoltage machines (cobalt-60 machine or linear accelerator $\geq 6 \mathrm{MV}$ photon). Initially the treatment volume included the contrast enhancing lesion and surrounding edema on CT or MRI with a $3 \mathrm{~cm}$ margin to a total dose of $40 \mathrm{~Gy}, 2$ Gy per fraction, 1 fraction per day, and five days per week. Subsequently, the target volume was reduced to include the enhancing lesion only (without edema) with a $2 \mathrm{~cm}$ margin to a total dose of $60 \mathrm{~Gy} / 2 \mathrm{~Gy} /$ fraction / 6 weeks. Traditionally, the patients were treated through two parallel-opposed portals with the tumor dose calculated at the midline on the central axis of the beam. Anticonvulsant and corticosteroids were administered as needed.

In the chemoradiation group, the patient received concurrently during the radiation course and starting from the first day of radiation, oral TMZ $150 \mathrm{mg} / \mathrm{m}^{2}$ daily, one hour before breakfasti.e. on empty stomach, for 5 days and repeated after 28 days for two cycles. Four weeks after radiotherapy, patients received adjuvant TMZ $\left(200 \mathrm{mg} / \mathrm{m}^{2}\right)$ daily for five days every 28 days for 6 cycles. Laboratory tests including complete blood picture, liver function and kidney function tests, were performed before each cycle of chemotherapy and adjustment of the dose was done according to table 1 . The drug was supplied in form of $50 \mathrm{mg}, 100 \mathrm{mg}$ or $200 \mathrm{mg}$ capsules.

The patients were examined generally and neurologically at weekly intervals till the end of the treatment and then every three month after finishing the treatment. Radiological assent by MRI and/or CT were performed 6 weeks after completion of irradiation, every three month as a follow up or if the patient developed progressive neurological symptoms or signs.

Table 1: TMZ dose adjustment criteria.

\begin{tabular}{|c|c|c|c|}
\hline $\begin{array}{l}\text { Nadir toxicity } \\
\text { level }\end{array}$ & $\begin{array}{l}\text { Nadir absolute } \\
\text { neutrophil } \\
\text { count } / \mathbf{m m}^{3}\end{array}$ & $\begin{array}{c}\text { Nadir } \\
\text { platelets } / \mathbf{m m}^{3}\end{array}$ & $\begin{array}{c}\text { TMZ } \\
\text { modification }\end{array}$ \\
\hline 0 & $\geq 2000$ & $\geq 1000,000$ & \multirow{3}{*}{$\begin{array}{l}\text { Full dose } \\
\text { daily }\end{array}$} \\
\hline 1 & $1,500-1,999$ & $75,000-99,999$ & \\
\hline 2 & $1,000-1,499$ & $50,000-74,999$ & \\
\hline 3 & 500-999 & $25,000-49,999$ & $\begin{array}{l}\text { Decrease dose } \\
\text { to } 25 \% \text { of the } \\
\text { original dose } \\
\text { level }\end{array}$ \\
\hline 4 & $<500$ & $<25,000$ & $\begin{array}{l}\text { Decrease dose } \\
\text { to } 50 \% \text { of the } \\
\text { original dose } \\
\text { level }\end{array}$ \\
\hline
\end{tabular}




\section{Evaluation of Response:}

Response criteria were evaluated from radiological brain imaging (including CT and gadolinium enhanced MRI) together with clinical responses by assessing the patient performance status and steroid dependence after treatment ${ }^{25}$. The responses were then graded into four categories:

\section{Complete Response (CR):}

Disappearance of all enhancing tumor on consecutive brain imaging scans, not receiving corticosteroids, and neurologically stable or improved.

\section{Partial Response (PR):}

$>50 \%$ reduction in size of enhancing tumor on consecutive brain scan, corticosteroid dosage stable or reduced, and neurologically stable or improved.

\section{Progressive Disease (PD):}

$>25 \%$ increase in the size of enhancing tumor or any new tumor on brain scans, or neurologically worse, and corticosteroid dosage stable or increased.

\section{Stable Disease (SD):}

\section{Survival and progression free survival:}

Survival was measured from the date of entry into the trial until death or last follow-up. Progression free survival (PFS) was measured from the date of entry into the trial until date of first evidence of disease progression or death from disease. Survival curves were calculated by the Kaplan-Meier method ${ }^{26}$. The comparison of patient characteristics was carried out using the two test for the categoric variables (sex, resection) and using a test for the continuous variables (time from diagnosis to treatment). Age and performance status were transformed to binary variables with cutoff points of 50 years and Karnofsky status of 80 , respectively ${ }^{27}$.

\section{Assessment of normal tissue toxicity:}

Toxicity was evaluated according to National Cancer institute $(\mathrm{NCI})$ criteria $^{28}$.

\section{RESULTS}

The present study included 44 patients, 21 in radiation group and 23 in chemoradiation group. There were no statistically significant differences in the demographic and baseline characteristics of the two treatment groups (Table 2 ). The median age was 46.6 years, ranged from
(25-65 years), in radiation group and 45.3 years, ranged from (24-61 years), in chemoradiation group. Eleven patients and 13 patients were younger than 50 years in radiation and chemoradiation groups, respectively. There were 12 males and 9 females in radiation group and 15 males and 8 females in chemoradiation group. Nine patients had good performance status (i.e. $>80$ on Karnofsky scale) in both groups. At presentation, 19 patients underwent biopsy only and 25 patients underwent subtotal resection of the primary tumor in both groups.

Table 2: Patient demographics and baseline disease characteristics.

\begin{tabular}{lcc}
\hline Characteristic & Radiation group & $\begin{array}{c}\text { Chemoradiation } \\
\text { group }\end{array}$ \\
\hline Number & 21 & 23 \\
Age & & \\
$\quad$ Range (years) & $25-65$ & $24-61$ \\
Median (years) & 46.6 & 45.3 \\
$<50$ years & $11(52 \%)$ & $13(56.5 \%)$ \\
$\geq 50$ years & $10(48 \%)$ & $10(43.5 \%)$ \\
Sex & $12(57 \%)$ & $15(65 \%)$ \\
Male & $9(43 \%)$ & $8(35 \%)$ \\
Female & & $5(22 \%)$ \\
Karnosky states & $4(19 \%)$ & $12(52 \%)$ \\
90 & $9(43 \%)$ & $6(26 \%)$ \\
80 & $8(38 \%)$ & $11(48 \%)$ \\
70 & & $12(52 \%)$ \\
Surgery at initial & & \\
diagnosis & $13(62 \%)$ & \\
Biopsy & &
\end{tabular}

\section{Tumor response:}

No recorded complete response in radiation group. Two patients in the chemoradiation group had radiological and clinical complete response. Seven patient $(33 \%)$ and 10 patients $(43.5 \%)$ in radiation group and chemoradiation group had partial response respectively, the difference was statistically insignificant. In addition, 9 patients (43\%) and 7 patients (30\%) in radiation and chemoradiation groups respectively had stable disease, the difference was statitically insignificant. Five patients $(24 \%)$ in radiation group and 4 patients $(17 \%)$ in chemoradiation group failed to respond to treatment with disease progression, the difference was statitically insignificant (Table 3 ).

Table 3: Response criteria.

\begin{tabular}{lccc}
\hline Response & $\begin{array}{c}\text { Radiation } \\
\text { group }\end{array}$ & $\begin{array}{c}\text { Chemoradiation } \\
\text { group }\end{array}$ & P-value \\
\hline CR & -- & $2(8.5 \%)$ & 0.9 \\
PR & $7(33 \%)$ & $10(43.5 \%)$ & 0.7 \\
PD & $5(24 \%)$ & $4(17 \%)$ & 0.9 \\
SD & $9(43 \%)$ & $7(30 \%)$ & 0.6 \\
\hline
\end{tabular}




\section{Survival and progression free survival:}

The median follow up was 8 months (range from 5 17 months) in radiation group and 12.8 months (range from 8-30 months) in chemoradiation group. The median survival was 8.5 months $(95 \%$ confidence internval $6.32-10.68)$ in radiation group vs. 12.6 months $(95 \%$ confidence internval $9.41-15.77)$ in chemoradiation group. The median PFS was 6.3 months $(95 \%$ confidence internval 3.43-9.23) in radiation group vs. 10.5 months (95\% confidence internval 6.99-13.94) in chemoradiation group. The overall survival (Figure 1) at 12 months were $23.5 \%$ and $43.5 \%$ in radiation and in chemoradiation group, respectively, the difference was statistically significant $(\mathrm{P}=0.04)$. The PFS (Figure 2 ) at 12 months was $0 \%$ in radiation group and $21 \%$ chemoradiation group, the difference was statistically significant $(\mathrm{P}=0.02)$.

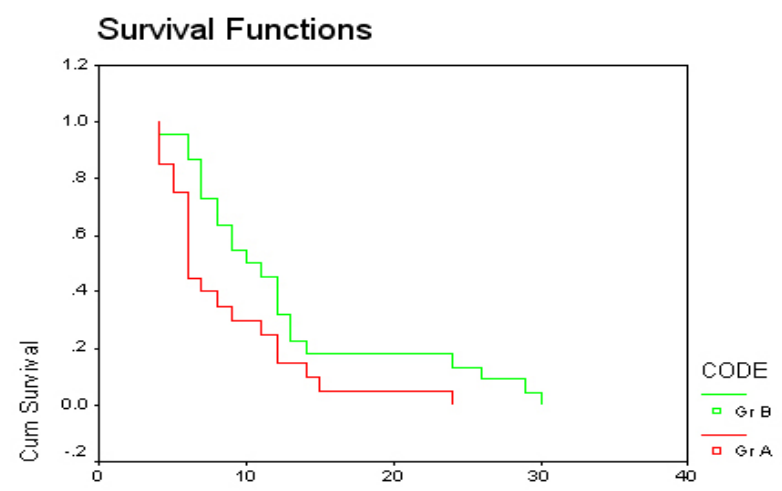

OS

Fig. 1: Kaplan Meier estimate of 12-month overall survival.

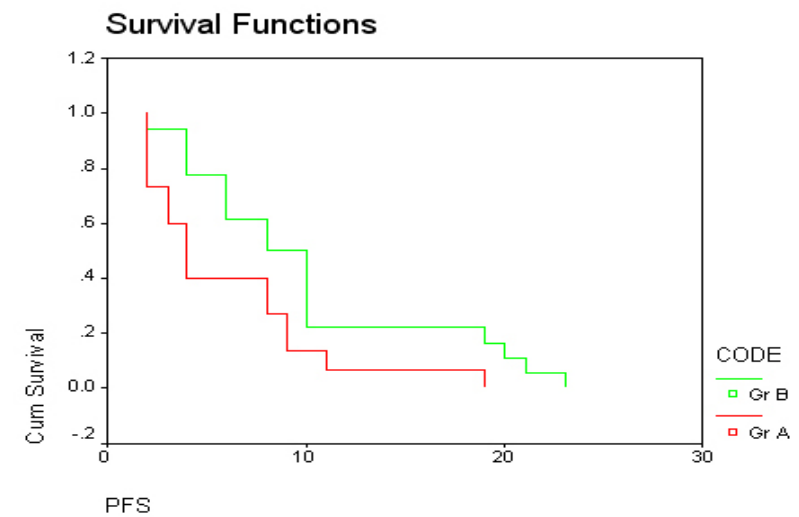

Fig. 2: Kaplan Meier estimate of 12-month progression free survival.

\section{Prognostic Factors:}

A univariate analysis to test the effect of different prognostic factors on overall survival for patients in chemoradiation group (Table 4) indicating that there were a trend towards better overall survival for young patients ( $<50$ years old), patients with good performance status (i.e. more than 80 on Karnofsky scale), and for patients underwent debulking surgery but the differences were not statistically significant.

Table 4: Prognostic factors for chemoradiation group.

\begin{tabular}{lcc}
\hline Factors & $\begin{array}{c}\text { 12 months- overall } \\
\text { survival }\end{array}$ & P-value \\
\hline Age & $7 / 13(54 \%)$ & 0.14 \\
$\quad<50$ years & $3 / 10(30 \%)$ & \\
$\quad \geq 50$ years & & \\
PS (Karnofsky & & \\
scale) & $5 / 5(100 \%)$ & 0.44 \\
$>80$ & $5 / 18(28 \%)$ & \\
$\quad \leq 80$ & & 0.8 \\
Type of resection & $4 / 11(36 \%)$ & \\
Biopsy & $6 / 12(50 \%)$ & \\
Debulking &
\end{tabular}

\section{Treatment Compliance and Toxicity:}

Grade three and four toxicity was not recorded in the radiation group. TMZ was safe and tolerable. In the chemoradiation group, 20 patients $(87 \%)$ received the 2 cycles of TMZ during radiotherapy course. Radiation course interruption, in chemoradiation group, was reported in only 3 patients $(13 \%)$ due to toxicity with dose reduction to $100 \mathrm{mg} / \mathrm{m}^{2}$ in $2^{\text {nd }}$ course. During adjuvant TMZ, 19 patients completed the 6 courses of chemotherapy. Four patients received only Two cycles of TMZ, two of them died because of tumor progression after the second cycle and two patients can not tolerate treatment. In the chemoradiation group, the main side effect was myelosuppression. Grade 3/4 hematologic toxicity was documented in three patients $(13 \%)$ during the concomitant course and in 6 patients $(26 \%)$ during the adjuvant TMZ course as shown in table 5 .

Table 5: Grade 3/4 toxicity in chemoradiation group according to National Cancer Institute (NCI) criteria.

\begin{tabular}{lcc}
\hline Toxicity & $\begin{array}{c}\text { Concomitant TMZ/ } \\
\text { Radiation }\end{array}$ & TMZ course \\
\hline Hematologic & $1(4.3 \%)$ & $2(8.7 \%)$ \\
Neutropenia & $2(8.7 \%)$ & $4(17.4 \%)$ \\
Thrombocytopenia & 0 & 0 \\
Anemia & --- & $2(8.7 \%)$ \\
Gastrointestinal & --- & --- \\
Nausea/ Vomiting & --- & -- \\
Constipation & & \\
Bilirubinemia &
\end{tabular}


During the concomitant administration of radiation and TMZ, grade 3/4 leukopenia demonstrated in one patients $(4.3 \%)$ and grade $3 / 4$ thrombocytopenia in two patients $(8.7 \%$ ) Grade 3/4 leukopenia during the adjuvant course was observed in two patients $(8.7 \%)$ and grade $3 / 4$ thrombocytopenia was observed in four patients $(17.4 \%)$. In the combined-therapy group, two patients (8.7\%) experienced grade $3 / 4$ treatment-related nausea and vomiting during the adjuvant course.

\section{DISCUSSION}

Glioblastoma multiforme (GBM) has a grave prognosis with relapse inevitably following surgery and radiation therapy. Many systemic agents have been explored in the treatment of GBM with the aim of improving outcome ${ }^{29-31}$.

Of the various chemotherapeutic agents tested, nitrosoureas for many decades are considered the most effective with a reported response rate between $10 \%-40 \%$. When administered in an adjuvant setting, their benefit in term of survival is small ${ }^{32-35}$ and in some studies, non existent ${ }^{29-37}$. The benefit of adjuvant nitrosourea based chemotherapy in patients with high grade gliomas has been confirmed in two large metaanalyses $^{33-35}$. These meta-analyses suggested only $6 \%$ to $10 \%$ increase in the proportion of patients surviving for 1 year. Median survival was 12 months for patients treated with radiotherapy plus chemotherapy and 9.4 months for patients treated with radiation only.

The concept of radiotherapy administered concomitantly with chemotherapy has been explored by using several agents with radiosensitizing properties but the results were not encouraging ${ }^{38-41}$. Kleinberg et al. reported a median survival of 12.8 months for patients treated with concomitant radiotherapy plus cisplatin and $\mathrm{BCNU}^{42}$.

The combined use of concomitant TMZ and radiation followed by adjuvant TMZ had been confirmed in two important randomized trials ${ }^{2,23}$. Both trials had the same design. An EORTC phase III trial ${ }^{23}$ included 573 patients while Athanassiou et al. trial ${ }^{2}$ included 110 patients with newly diagnosed GBM. In both trials, the patients were randomly assigned to either standard RT (60 Gy in 30 daily fractions of 2 Gy) or the concomitant daily TMZ $\left(75 \mathrm{mg} / \mathrm{m}^{2} /\right.$ day) and conventionally fractionated irradiation followed by 6 cycles of adjuvant TMZ (200 $\mathrm{mg} / \mathrm{m}^{2}$ /day for five days every 28 days). In both of these trials, tumor response was not an end point. The tumor responses in our study were not encouraging. No recorded complete response in radiation group. Two patients in the chemoradiation group had complete response. Seven patient $(33 \%)$ and 10 patients $(43.5 \%)$ in radiation and chemoradiation groups, respectively, had partial response, the differences were statistically insignificant. This can be explained by the fact that contrast enhancement on CT or MRI, while not a true representation of tumor size as it demonstrates the region of blood brain barrier disruption, is accepted as a surrogate for tumor size. However as the size of region of enhancement is altered by surgery, radiotherapy and by the use of steroids, it is an unreliable measure for tumor response.

Our randomized study confirmed the superiority of the concomitant $\mathrm{TMZ}$ and radiation followed by adjuvant TMZ regimen over RT alone, which supports the final data of EORTC ${ }^{23}$ and Athanassiou et al. ${ }^{2}$ trials. The EORTC trial demonstrated that the combined treatment, compared with RT alone, significantly improved median survival (12 vs. 14.6 months, respectively), median PFS (5 vs. 6.9 months, respectively) and the 2-year overall survival, ( $10.4 \%$ vs. $26.5 \%$, respectively). The Athanassiou et al. ${ }^{2}$ trial demonstrated that the combined treatment, compared with RT alone, significantly improved median survival (7.7 vs. 13.4 months, respectively), median PFS (5.2 vs. 10.8 months, respectively), and the 18 -months overall survival $(5.38 \%$ vs. $24.9 \%$, respectively). In the present study, the median survival and the median PFS in the combined group (12.6 months and 10.5 months, respectively) compared significantly with the results of radiation group ( 8.5 months and 6.3 months, respectively) but still inferior to that reported in EORTC trial. This can be explained by the following factors. First, In EORTC trial, the patients were a relatively healthy group; $64 \%$ of patients had a good performance status (Karnofsky >80) compared with only $22 \%$ of patient in the present study. Second, $84 \%$ of patients underwent debulking surgery in EORTC trial compared to only $52 \%$ in our study. Third, dose intensity, temozolomide may be more effective if given on daily basis during radiation as in EORTC trial than on intermittent basis.

In our study, there were a tendency for better overall survival for, healthy patients (performance status $>80$ ), young patients $(<50$ years old), and those underwent debulking surgery. However, the differences were not statistically significant mainly because of small numbers of patients. The multivariate analysis of prognostic factors in Athanassiou et al. trial ${ }^{2}$ demonstrated that the administration of TMZ, age and performance status were the significant prognostic factor for better survival. In EORTC trial $^{23}$, they demonstrated additionally that a significant increase in median survival with debulking surgery compared with biopsy alone.

Grade 3/4 toxicity was not recorded in the radiation group. The incidence of drug-related toxic effects in this study was extremely low and manageable, even when temozolomide was administered concomitantly with radiotherapy. The main side effect in chemoradiation group was myelosuppression that was reversible and noncumulative, which allowed for nearly continuous therapy. Grade 3/4 hematologic toxicity was documented 
in three patients $(13 \%)$ during the concomitant course and in 6 patients $(26 \%)$ during the adjuvant TMZ course. Radiation course interruption, in chemoradiation group, was reported in only three patients $(13 \%)$ due to toxicity. Nonhematologic adverse effects occurred with low frequency. Grade 3/4 nausea and vomiting were virtually eliminated with standard antiemetics. EORTC trial ${ }^{23}$ and Athanassiou et al. trial $^{2}$ had the same low toxicity profile.

\section{CONCLUSION}

The results of our study suggested that concomitant radiation and TMZ followed by 6 cycles of adjuvant $\mathrm{TMZ}$ is superior to radiation alone in patients with newly diagnosed GBM. In addition, TMZ was safe and tolerable. Nevertheless, the challenge remains to improve clinical outcomes further.

\section{REFERENCES}

1. Levin VA, Leibel SA, Gutin PH, et al. Neoplasms of the central nervous system. In: DeVita VT Jr, Hellman S, Rosenberg SA, editors. Cancer: principles and practice of oncology. $6^{\text {th }}$ ed. Philadelphia, PA: Lippicott Williams and Wilkins; 2001. p. 210061.

2. Athanassiou H, Synodinou M, Maragoudakis E, Paraskevaidis M, Verigos C, Misailidou D, et al. Randomized phase II study of temozolomide and radiotherapy compared with radiotherapy alone in newly diagnosed glioblastoma multiforme. J Clin Oncol 2005 Apr 1;23(10):2372-77.

3. DeAngelis LM. Benefits of adjuvant chemotherapy in high-grade gliomas. Semin Oncol 2003 Dec;30(6 Suppl 19):15-18.

4. Mirimanoff RO, Gorlia T, Mason W, Van den Bent MJ, Kortmann RD, Fisher B, et al. Radiotherapy and temozolomide for newly diagnosed glioblastoma: Recursive partitioning analysis of the EORTC 26981/22981-NCIC CE3 phase III randomized trial. J Clin Oncol 2006 Jun 1;24(16):2563-69.

5. Walker MD, Alexander E,Jr, Hunt WE, MacCarty CS, Mahaley $\mathrm{MS}, \mathrm{Jr}$, Mealey J,Jr, et al. Evaluation of BCNU and/or radiotherapy in the treatment of anaplastic gliomas. A cooperative clinical trial. J Neurosurg 1978 Sep;49(3):333-43.

6. Walker MD, Strike TA, Sheline GE. An analysis of dose-effect relationship in the radiotherapy of malignant gliomas. Int J Radiat Oncol Biol Phys 1979 Oct;5(10):1725-31.

7. Cokgor I, Friedman HS, Friedman AH. Chemotherapy for adults with malignant glioma. Cancer Invest 1999;17(4):264-72.

8. Levin VA, Leibel SA, Gutin PH et al. Neoplasms of the central nervous system. In: DeVita VT, Hellman S, Rosenberg SA, editors. Cancer: Principles and practice of oncology. $5^{\text {th }}$ ed. Philadelphia: J.B. Lippicott; 1997. p. 2022-82.
9. Friedman HS, Kerby T, Calvert H. Temozolomide and treatment of malignant glioma. Clin Cancer Res 2000 Jul;6(7):2585-97.

10. Schold SC,Jr, Brent TP, von Hofe E, Friedman HS, Mitra S, Bigner DD, et al. O6-alkylguanine-DNA alkyltransferase and sensitivity to procarbazine in human brain-tumor xenografts. J Neurosurg 1989 Apr;70(4):573-77.

11. Newlands ES, O'Reilly SM, Glaser MG, Bower M, Evans H, Brock C, et al. The Charing Cross Hospital experience with temozolomide in patients with gliomas. Eur J Cancer 1996 Dec;32A(13):2236-41.

12. Bower M, Newlands ES, Bleehen NM, Brada M, Begent RJ, Calvert $\mathrm{H}$, et al. Multicentre CRC phase II trial of temozolomide in recurrent or progressive high-grade glioma. Cancer Chemother Pharmacol 1997;40(6):484-88

13. Yung WK, Albright RE, Olson J, Fredericks R, Fink K, Prados $\mathrm{MD}$, et al. A phase II study of temozolomide vs. procarbazine in patients with glioblastoma multiforme at first relapse. Br J Cancer 2000 Sep;83(5):588-93.

14. Esteller M, Garcia Foncillas J, Andion E, Goodman SN, Hidalgo $\mathrm{OF}$, Vanaclocha $\mathrm{V}$, et al. Inactivation of the DNA-repair gene MGMT and the clinical response of gliomas to alkylating agents. N Engl J Med 2000 Nov 9;343(19):1350-54.

15. Tolcher AW, Gerson SL, Denis L, Geyer C, Hammond LA, Patnaik A, et al. Marked inactivation of O6-alkylguanine-DNA alkyltransferase activity with protracted temozolomide schedules. Br J Cancer 2003 Apr 7;88(7):1004-11.

16. Hegi ME, Diserens AC, Godard S, Dietrich PY, Regli L, Ostermann $\mathrm{S}$, et al. Clinical trial substantiates the predictive value of O-6-methylguanine-DNA methyltransferase promoter methylation in glioblastoma patients treated with temozolomide. Clin Cancer Res 2004 Mar 15;10(6):1871-74.

17. Hegi ME, Diserens AC, Gorlia T, Hamou MF, de Tribolet N, Weller $\mathrm{M}$, et al. MGMT gene silencing and benefit from temozolomide in glioblastoma. N Engl J Med 2005 Mar 10;352(10):997-1003.

18. Van Rijn J, Heimans JJ, van den Berg J, van der Valk P, Slotman BJ. Survival of human glioma cells treated with various combination of temozolomide and X-rays. Int J Radiat Oncol Biol Phys 2000 Jun 1;47(3):779-84.

19. Gilbert M, O’Neill A, Grossman S, Grunnet M, Mehta M, Jubelirer $\mathrm{S}$, et al. A phase II study of preradiation chemotherapy followed by external beam radiotherapy for the treatment of patients with newly diagnosed glioblastoma multiforme: An Eastern Cooperative Oncology Group study (E2393). J Neurooncol 2000 Apr;47(2):145-52.

20. Gilbert MR, Friedman HS, Kuttesch JF, Prados MD, Olson JJ, Reaman GH, et al. A phase II study of temozolomide in patients with newly diagnosed supratentorial malignant glioma before 
radiation therapy. Neuro oncol 2002 Oct;4(4):261-67.

21. Brada M, Ashley S, Dowe A, Gonsalves A, Huchet A, Pesce G, et al. Neoadjuvant phase II multicentre study of new agents in patients with malignant glioma after minimal surgery. Report of a cohort of 187 patients treated with temozolomide. Ann Oncol 2005 Jun;16(6):942-49.

22. Stupp R, Dietrich PY, Ostermann Kraljevic S, Pica A, Maillard I, Maeder P, et al. Promising survival for patients with newly diagnosed glioblastoma multiforme treated with concomitant radiation plus temozolomide followed by adjuvant temozolomide. J Clin Oncol 2002 Mar 1;20(5):1375-82.

23. Stupp R, Mason WP, Van Den Bent MJ, Weller M, Fisher B, Taphoorn MJ, et al. Radiotherapy plus concomitant and adjuvant temozolomide for glioblastoma. N Engl J Med 2005 Mar 10;352(10):987-96.

24. El-Ghunaimi E. Concurrent temozolomide (TMZ) and irradiation for the management of high grade malignant glioma. Med J Cairo Univ 2003 Jun;71(2 suppl):147-56.

25. Macdonald DR, Cascino TL, Schold SC,Jr, Cairncross JG. Response criteria for phase II studies of supratentorial malignant glioma. J Clin Oncol 1990 Jul;8(7):1277-80.

26. Kaplan EL, Meier P. Nonparametric Estimation from Incomplete Observations. J Am Stat Assoc 1958 Jun;53(282):457-81.

27. Peto R, Pike MC, Armitage P, Breslow NE, Cox DR, Howard SV, et al. Design and analysis of randomized clinical trials requiring prolonged observation of each patient. II. analysis and examples. Br J Cancer 1977 Jan;35(1):1-39.

28. Baquiran DC. National Cancer Institute toxicity scale. In: Baquiran DC, editor. Lippincott's Cancer Chemotherapy Handbook. $2^{\text {nd }}$ ed. Philadelphia: Lippincott; 2001. p. 414-93.

29. Henson JW. Treatment of glioblastoma multiforme: A new standard. Arch Neurol 2006 Mar;63(3):337-41.

30. Reardon DA, Rich JN, Friedman HS, Bigner DD. Recent advances in the treatment of malignant astrocytoma. J Clin Oncol 2006 Mar 10;24(8):1253-65.

31. Wang L, Wei Q, Wang LE, Aldape KD, Cao Y, Okcu MF, et al. Survival prediction in patients with glioblastoma multiforme by human telomerase genetic variation. J Clin Oncol 2006 Apr 1;24(10):1627-32.

32. Walker MD, Green SB, Byar DP, Alexander E Batzdorf U, Brooks WH, et al. Randomized comparisons of radiotherapy and nitrosoureas for the treatment of malignant glioma after surgery. N Engl J Med 1980 Dec 4;303(23):1323-29.
33. Fine HA, Dear KB, Loeffler JS, Black PM, Canellos GP. Meta-analysis of radiation therapy with and without adjuvant chemotherapy for malignant gliomas in adults. Cancer 1993 Apr $15 ; 71(8): 2585-97$.

34. Hildebrand J, Sahmoud T, Mignolet F, Brucher JM, Afra D. Adjuvant therapy with dibromodulcitol and BCNU increases survival of adults with malignant gliomas. EORTC Brain Tumor Group. Neurology 1994 Aug;44(8):1479-83.

35. Stewart LA. Chemotherapy in adult high-grade glioma: A systematic review and meta -analysis of individual patient data from 12 randomised trials. Lancet 2002;359(9311):1011-18.

36. Medical Research Council Brain Tumor Working Party. Randomized trial of procarbazine, lomustine, and vincristine in the adjuvant treatment of high-grade astrocytoma: A Medical Research Council trial. J Clin Oncol 2001 Jan 15;19(2):509-18.

37. Grossman SA. Arguments against the routine use of currently available adjuvant chemotherapy in high-grade gliomas. Semin Oncol 2003 Dec;30(6 Suppl 19):19-22.

38. Grossman SA, Wharam M, Sheidler V, Kleinberg L, Zeltzman $\mathrm{M}$, Yue N, et al. Phase II study of continuous infusion carmustine and cisplatin followed by cranial irradiation in adults with newly diagnosed high-grade astrocytoma. J Clin Oncol 1997 Jul;15(7):2596-2603.

39. Del Rowe J, Scott C, Werner Wasik M, Bahary JP, Curran WJ, Urtasun RC, et al. Single-arm, open-label phase II study of intravenously administered tirapazamine and radiation therapy for glioblastoma multiforme. J Clin Oncol 2000 Mar;18(6):125459.

40. Fisher BJ, Scott C, Macdonald DR, Coughlin C, Curran WJ. Phase I study of topotecan plus cranial radiation for glioblastoma multiforme: esults of Radiation Therapy Oncology Group Trial 9507. J Clin Oncol 2001 Feb 15;19(4):1111-17.

41. Grossman SA, O’Neill A, Grunnet M, Mehta M, Pearlman JL, Wagner $\mathrm{H}$, et al. Phase III study comparing three cycles of infusional carmustine and cisplatin followed by radiation therapy with radiation therapy and concurrent carmustine in patients with newly diagnosed supratentorial glioblastoma multiforme: Eastern Cooperative Oncology Group Trial 2394. J Clin Oncol 2003 Apr 15;21(8):1485-91.

42. Kleinberg L, Grossman SA, Piantadosi S, Zeltzman M, Wharam M. The effects of sequential versus concurrent chemotherapy and radiotherapy on survival and toxicity in patients with newly diagnosed high-grade astrocytoma. Int J Radiat Oncol Biol Phys 1999 Jun 1;44(3):535-43. 